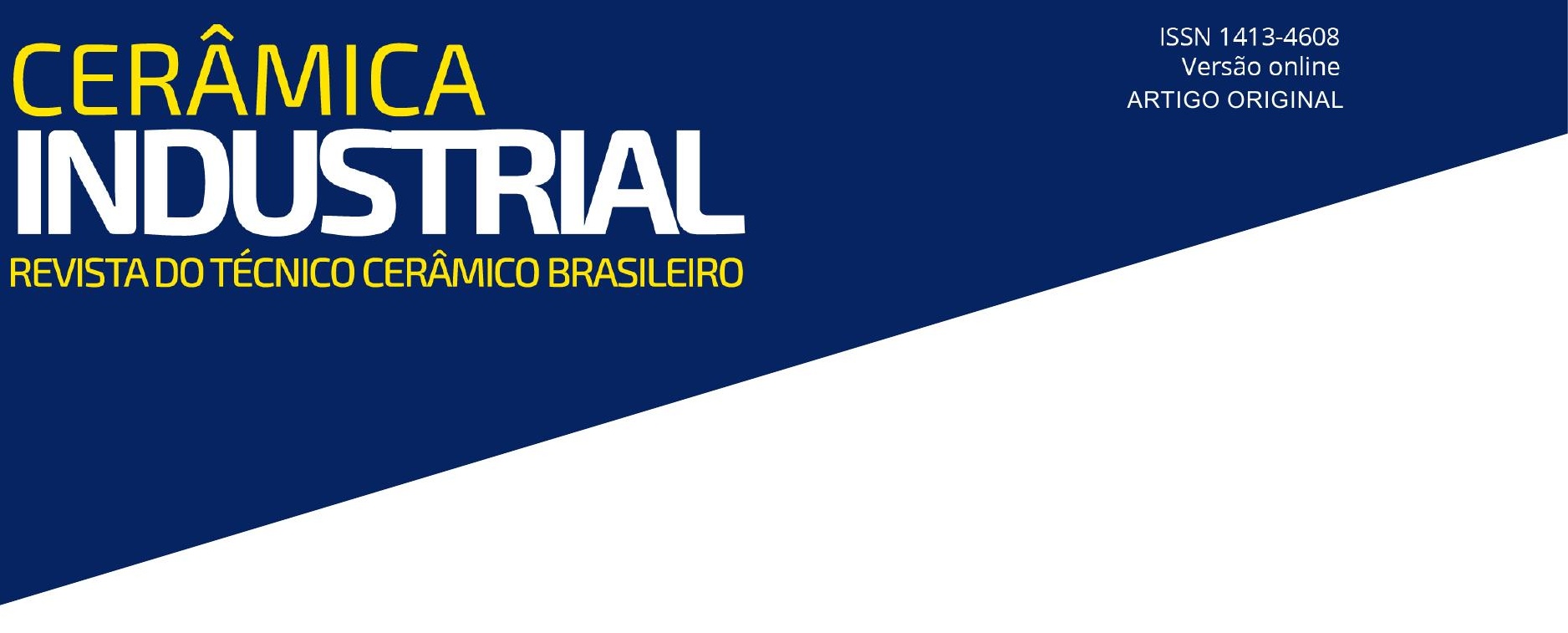

\title{
Avaliação das tensões nas camadas de revestimento cerâmico após indução de aquecimento superficial em diferentes condições
}

\author{
Renan Pereira de Andrade ${ }^{1 *}$; Henrique Chiaradia Falcão $\mathrm{Curci}^{2}$; Ellen Soares Silva de Moura ; \\ Henrique Campelo Gomes²; Flávio Leal Maranhão \\ ${ }^{1}$ Escola Politécnica da Universidade de São Paulo - Departamento de Engenharia da Construção \\ ${ }^{2}$ Escola Politécnica da Universidade de São Paulo - Departamento de Engenharia de Estruturas e Geotécnica \\ *e-mail: renanandradep@outlook.com
}

\section{Resumo:}

Este trabalho apresenta estudo do comportamento mecânico de um sistema de revestimento cerâmico aderido (SRCA) submetido a diferentes condições de aquecimento a partir de ensaios experimentais com utilização de protótipos em escala real e modelagem computacional. Como metodologia, foi desenvolvido um protótipo de SRCA e suas respectivas interfaces instrumentadas com sensores de temperatura de modo a ser possível avaliar a troca térmica entre as camadas e dar subsídio para o processo de modelagem computacional com dados reais. A modelagem foi realizada pelo Método dos Elementos Finitos (MEF) e contempla a análise bidimensional do conjunto de camadas do SRCA com dimensões similares a do protótipo, por meio de uma rotina de processamento desenvolvida e validada pelos autores. As propriedades mecânicas de cada material foram medidas em laboratório e obtidas da literatura para alimentar o modelo computacional proposto. Como parte dos resultados, são evidenciados picos de tensão na interface entre revestimento e argamassa encontrados tanto nos modelos numéricos quanto no protótipo. É observada fissuração das juntas de assentamento e outras ocasionadas pelos elementos da alvenaria após ciclos de aquecimento. A elevação da temperatura das camadas ocasiona elevação das tensões principais. As bordas dos elementos presentes em um SRCA apresentaram grande interferência para o surgimento e concentração de tensões. Concentrações que podem chegar a tensões principais de tração e compressão de até 2,38 MPa e 2,05 MPa, além de tensões de cisalhamento de até 5,0 MPa e, portanto, muito maiores que as propriedades dos respectivos materiais. Em situações reais, estas tensões podem colaborar para a propagação de dano e acelerar a manifestação de fissuras e destacamentos, por exemplo.

Palavras-chave: revestimentos cerâmicos; presença de danos; fissuras; manifestações patológicas.

\section{INTRODUÇÃo}

Os sistemas de revestimentos cerâmicos aderidos (SRCA) estão muitas vezes expostos à ação de diversos agentes agressivos como impactos, abrasões, ataques químicos, poluentes, variações bruscas de temperatura e ciclos de molhagem e secagem. Isso se observa ainda mais naqueles presentes nas fachadas dos edifícios, evidenciando a grande frequência de casos de danos observados que resultam em fissuras, infiltrações e descolamentos [1-4]. Os SRCA são sistemas multicamadas constituídos por uma base, tradicionalmente feita em alvenaria ou concreto; uma camada de regularização (emboço); camada adesiva, comumente executadas em argamassas colantes ou resinas adesivas, e camada de 
revestimento, composta por placas cerâmicas e juntas de assentamento rejuntadas. Dessa forma, a presença de interface entre estas camadas é inevitável, mas também fundamental para o devido funcionamento do sistema.

Quando expostas a variações de temperatura, as diferentes camadas sofrem expansões térmicas cujas magnitudes dependem de suas propriedades mecânicas e térmicas, como o módulo de Young $(E)$, o coeficiente de Poisson $(v)$ e o coeficiente de deformação térmica linear $(\alpha)$, específicas para cada material. Restrições de deslocamentos nas interfaces entre as camadas, uma vez aderidas umas às outras, juntamente com aquecimento ou resfriamento desigual ao longo da espessura dos SRCA, geram deformações diferenciais que, por consequência, ocasionam tensões normais e tangenciais. Quando as tensões atuantes em determinada camada superam o limite de resistência do material que a compõe, surge uma falha. Esta falha pode ficar restrita a uma pequena região, sem consequências práticas para o revestimento, ou podem se propagar ao longo dos ciclos térmicos [5].

Diversos trabalhos experimentais já comprovaram a queda de desempenho em sistemas de revestimentos quando submetidos a variações térmicas por meio da propagação de danos. Yiu, Ho e Lo [6] e Andrade et al. [7] mediram reduções superiores a 50\% na resistência ao cisalhamento e de aderência à tração, respectivamente, quando submetidos a pouco mais de 100 ciclos de aquecimento e resfriamento acelerado em ambiente laboratoriais.

Nas últimas duas décadas, tem-se evidenciado um crescente interesse pela abordagem computacional para modelagem das deformações e tensões nesses sistemas. Uma das principais publicações foi feita por Mahaboonpachai et al. [8] que a partir de expressões analíticas e posterior análise da energia e modos de fratura nas interfaces pode mostrar áreas com maiores concentrações e propagações de danos através de modelos matemáticos. Os autores constataram que a expansão diferencial entre as camadas constitui um dos principais fatores de degradação dos SRCA, pois acelera a propagação de fissuras e consequentemente a perda de aderência. Outra importante abordagem foi realizada por Felixberger [9] que avaliou a influência da espessura da camada de argamassa colante, das dimensões das placas cerâmicas e das propriedades mecânicas dos materiais. $O$ autor conclui que características como a posição e picos de maiores tensões de cisalhamento em geral, se encontram nas bordas dos revestimentos. Mais recentemente, diversos trabalhos da universidade de Bern abordaram o tema, destacando-se Herwegh et al. [10] que baseado em modelagem numérica computacional de duas dimensões propôs que a deformação imposta pela retração da argamassa colante e os vazios deixados por assentamento imperfeito são os fatores que exercem maior influência na queda de desempenho dos SRCA. Zurbriggen e Herwegh [11] apresentaram mapas de distribuição de tensão nos sistemas de revestimentos destacando que nas bordas das placas cerâmicas estão os pontos com tração mais elevadas.

Apesar de todos esses avanços, incertezas ainda persistem quando os sistemas de revestimentos cerâmicos aderidos são submetidos a processos de aquecimento seguidos de resfriamento e os danos causado por ciclos destes processos. Por isso, essa pesquisa propõe avaliar como se comportam as diferentes camadas do SRCA quando submetidos a diferentes processos de aquecimento e resfriamento e quais as tensões originadas por meio dos gradientes térmicos mapeados em prototipagem de grandes dimensões.

\section{MATERIAIS E MÉTODOS}

O protótipo desenvolvido possui dimensões de $200 \mathrm{~cm}$ x $200 \mathrm{~cm}$ e foi instalado no interior de uma aduela pré-moldada de concreto armado com o objetivo de simular um SRCA confinado e restringir as deformações (Figura 1-a). O SRCA é composto por base em alvenaria com blocos cerâmicos na espessura de $14 \mathrm{~cm}$, camada de regularização (emboço) em argamassa industrializada com espessura de $2 \mathrm{~cm}$, camada revestida composta por argamassa colante ACII na espessura de $5 \mathrm{~mm}$, placas cerâmicas de $45 \mathrm{~cm} \times 45 \mathrm{~cm}$ e espessura de $6 \mathrm{~mm}$, de tipologia Bllb e, por fim, juntas entre placas de $4 \mathrm{~mm}$ preenchidas com material cimentício (Figura 1-b). A Figura 2-a apresenta a propriedade dos materiais e suas respectivas camadas e interfaces.

O aquecimento foi realizado por meio de painel radiante composto por lâmpadas halógenas com uma potência de aproximadamente $1875 \mathrm{~W} / \mathrm{m}^{2}$, monitoramento e controle de temperatura por meio de controlador lógico programável (CLP) monitorado por computadores (Figura 1-c) de maneira a se 
controlar as taxas pré-estabelecidas (Figura 1-c). O processo de resfriamento foi realizado por meio de aspersão por água sobre toda a superfície revestida. A aspersão se deu através da utilização de dutos posicionados superior ao protótipo. Uma vez acionada válvula solenoide, ocorre a liberação da água sobre o protótipo com formação de uma lâmina d'água de aproximadamente $4 \mathrm{~mm}$, projetada a uma vazão média de $35 \mathrm{~L} / \mathrm{min}$. Uma vez utilizada no processo de resfriamento, a água que cai sobre o chão é coletada através de valetas, filtrada e se desloca para um reservatório através da gravidade. O reservatório coleta a água já utilizada e através de sistema de resfriamento controlado efetua o decréscimo da temperatura da água para $20^{\circ} \mathrm{C}$. Por fim, a água contida no reservatório de armazenamento e resfriamento é utilizada novamente em um novo ciclo de resfriamento.

As interfaces entre camadas do SRCA foram instrumentadas com termopares tipo T, blindagem do fio condutor em teflon totalizando 4 pontos de monitoramento. A obtenção dos resultados tem taxa de aquisição de $5 \mathrm{~Hz}$. A Figura 2-b apresenta os pontos utilizados para medição da temperatura, sendo que o primeiro foi instalado na face da placa cerâmica (ponto 1), o segundo na interface argamassa colante/placa cerâmica (ponto 2), o terceiro na interface argamassa colante/emboço (ponto 3) e o quarto na interface emboço/alvenaria (ponto 4).

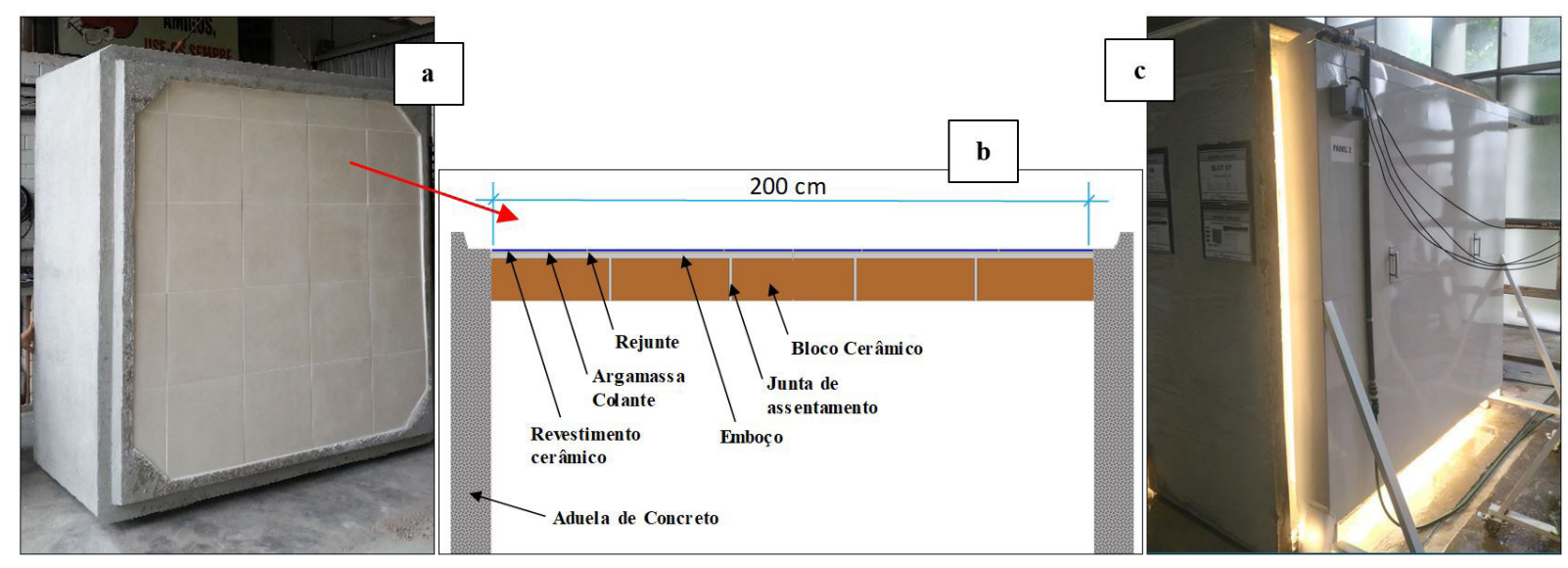

Figura 1 - (a) Protótipo executado interno a aduela de concreto. (b) Representação de corte horizontal a meia altura da aduela de concreto com camadas e interfaces, indicadas. (c) Painel de choque térmico e sistema de aquecimento e sistema de resfriamento por aspersão de água. Fonte: Autoria própria

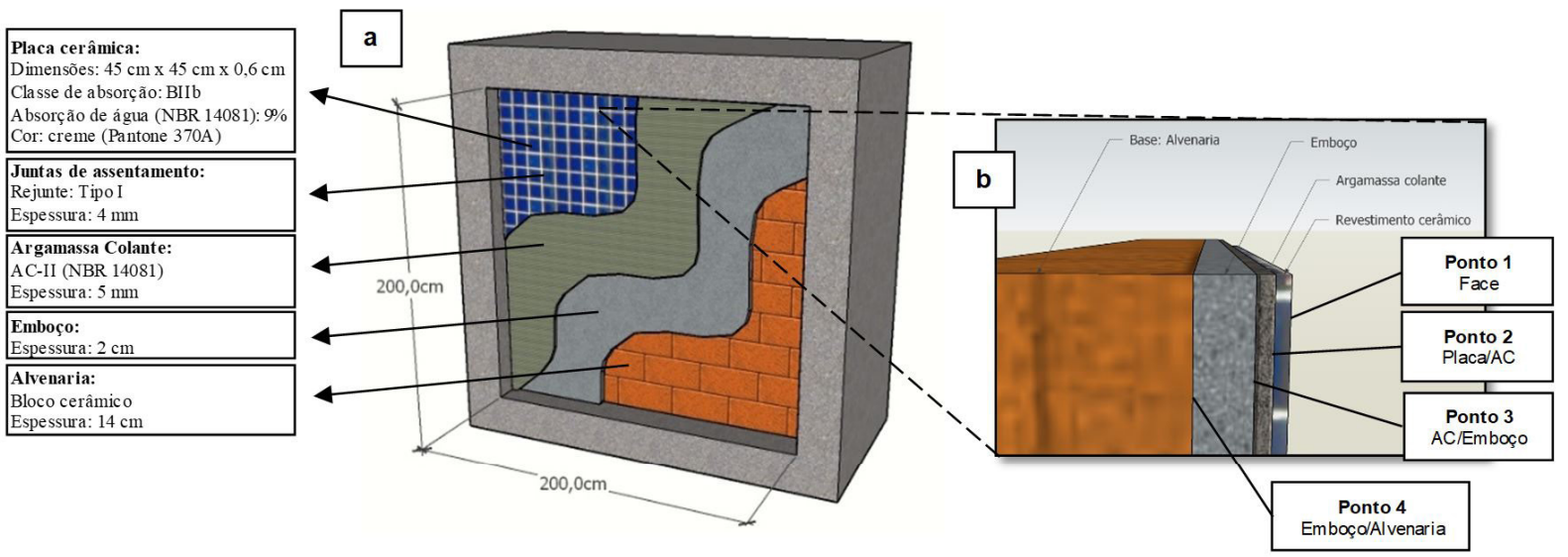

Figura 2. (a) Representação da aduela de concreto com camadas e propriedades indicadas. (b) Indicação dos pontos de instrumentação (termopares) nas interfaces da parede para obtenção do perfil de temperaturas do protótipo. 


\subsection{Hipóteses de ensaio}

Por simplicidade e considerando que os materiais entre duas interfaces analisadas sejam uniformes e homogêneos, foi considerada a interpolação dos valores nos pontos para se obter a temperatura em um ponto genérico ao longo da espessura do SRCA. Tal hipótese é importante na aplicação do método de obtenção das tensões, visto que todos os elementos da estrutura apresentam um valor de temperatura consistente com o observado em laboratório no processo de prototipagem.

Foram avaliados 3 diferentes comportamentos de aquecimento e resfriamento, aqui denominado de casos. Em todos eles a temperatura máxima atingida na superfície das placas cerâmicas foi de $83^{\circ} \mathrm{C}$, sendo variado o tempo em que permaneceu neste patamar de máxima temperatura e a presença de um resfriamento forçado por meio de uma lâmina de água até a temperatura superficial atingir $20^{\circ} \mathrm{C}$. A Tabela 1 apresenta esses 3 casos. Para a comparação das tensões geradas pelos efeitos térmicos foram escolhidos instantes específicos ( $\mathrm{T}$ ) durante o processo de aquecimento e resfriamento, os quais apresentaram as maiores diferenças de temperatura $(\Delta T)$ relativa entre as interfaces ou ainda pela relevância de sua compreensão.

O caso 1 é caracterizado por um aquecimento acelerado e em curto espaço de tempo. Neste caso o SRCA sai de sua temperatura ambiente $\left(\sim 22^{\circ} \mathrm{C}\right)$ e atinge a temperatura superficial máxima de $83^{\circ} \mathrm{C}$ em um período de $2 \mathrm{~h}$. É realizado o controle da temperatura por um período de $2,5 \mathrm{~h}$ até o início do resfriamento natural através do desligamento das lâmpadas de aquecimento.

O caso 2 é determinado pelo aquecimento gradual e prolongado do SRCA. Neste caso é proposto de controle da taxa de aquecimento de modo que demore $6 \mathrm{~h}$ para atingir a temperatura superficial máxima. Logo após este processo de aquecimento, é mantida a temperatura em $80 \pm 4{ }^{\circ} \mathrm{C}$ por um período de $7 \mathrm{~h}$ com posterior resfriamento natural.

O caso 3 se apresenta similar ao caso 1, exceto ao fato de apresentar processo de resfriamento forçado caracterizado por aspersão de água sobre a superfície de modo a criar uma lâmina de água responsável pelo resfriamento repentino do SRCA.

Tabela 1. Descrição das hipóteses em análise para processo de aquecimento/resfriamento adotados

\begin{tabular}{cccc} 
CASO & $\mathbf{1}$ & $\mathbf{2}$ & $\mathbf{3}$ \\
Tempo de aquecimento & $2 \mathrm{~h}$ & $6 \mathrm{~h}$ & $2 \mathrm{~h}$ \\
Patamar de estabilização & $2,5 \mathrm{~h}$ & $7 \mathrm{~h}$ & $2,5 \mathrm{~h}$ \\
Tipo de Resfriamento & natural & natural & forçado \\
\hline
\end{tabular}

\subsection{Análise Computacional pelo Método dos Elementos Finitos}

Métodos numéricos e computacionais são comumente usados na análise do estado de tensões de sólidos de sistemas estruturais. Quanto à aplicação desses métodos, o Método dos Elementos Finitos (MEF) é atualmente o mais utilizado por sua versatilidade na resolução de problemas de sistemas de equações diferenciais parciais. A obtenção do campo de deslocamentos é decorrente do equilíbrio de cada elemento do modelo, sendo que são esses elementos que apresentam as propriedades mecânicas e geométricas do material que o constitui. A implementação do método em si, bem como a aplicação e resolução do problema termo elástico proposto foram desenvolvidos com base nas formulações e deduções observadas em Fish e Belytschko [12] e Bower [13]. Toda a modelagem de elementos finitos foi realizada com um código FEM interno que é estruturado para análises de deformação termoelástica linear. Foi utilizado o MatchWorks MATLAB como ferramenta de implementação dos modelos matemáticos (solver) e tanto o pré quanto o pós-processamento foram desenvolvidos com o software GiD [14].

Para a verificação do estado de tensão do sistema de revestimento foi utilizado um modelo da parede sob hipótese de Estado Plano de Deformação (EPD). Para cada análise foram definidas as geometrias do problema, relacionadas as geometrias do protótipo laboratorial, as temperaturas interpoladas em cada nó do modelo e as características materiais de cada camada do SRCA. A malha de domínio bidimensional implementada no MEF foi gerada a partir da discretização do domínio por meio de elementos triangulares de seis nós, conforme indicado na representação genérica do domínio plano da Figura 3-a. A malha obtida foi refinada nas camadas do revestimento, da argamassa colante e do emboço, região onde a obtenção de um gradiente de tensões mais refinado é de maior 
AVALIAÇÃO DAS TENSÕES NAS CAMADAS DE REVESTIMENTO CERÂMICO APÓS INDUÇÃO DE AQUECIMENTO SUPERFICIAL EM DIFERENTES CONDIÇÕES

Andrade, R. P. et al.

interesse. Para tanto, os elementos nestas regiões têm dimensão máxima de $1 \mathrm{~mm}$ (Figura 3-b). 0 modelo contempla aproximadamente 40.000 elementos e aproximadamente 80.000 nós, totalizando uma matriz de aproximadamente 160.000 x 160.000 cálculos de tensões, levado em consideração o deslocamento em dois eixos do plano bidimensional. A Tabela 2 apresenta as propriedades dos materiais aplicados à modelagem em questão.

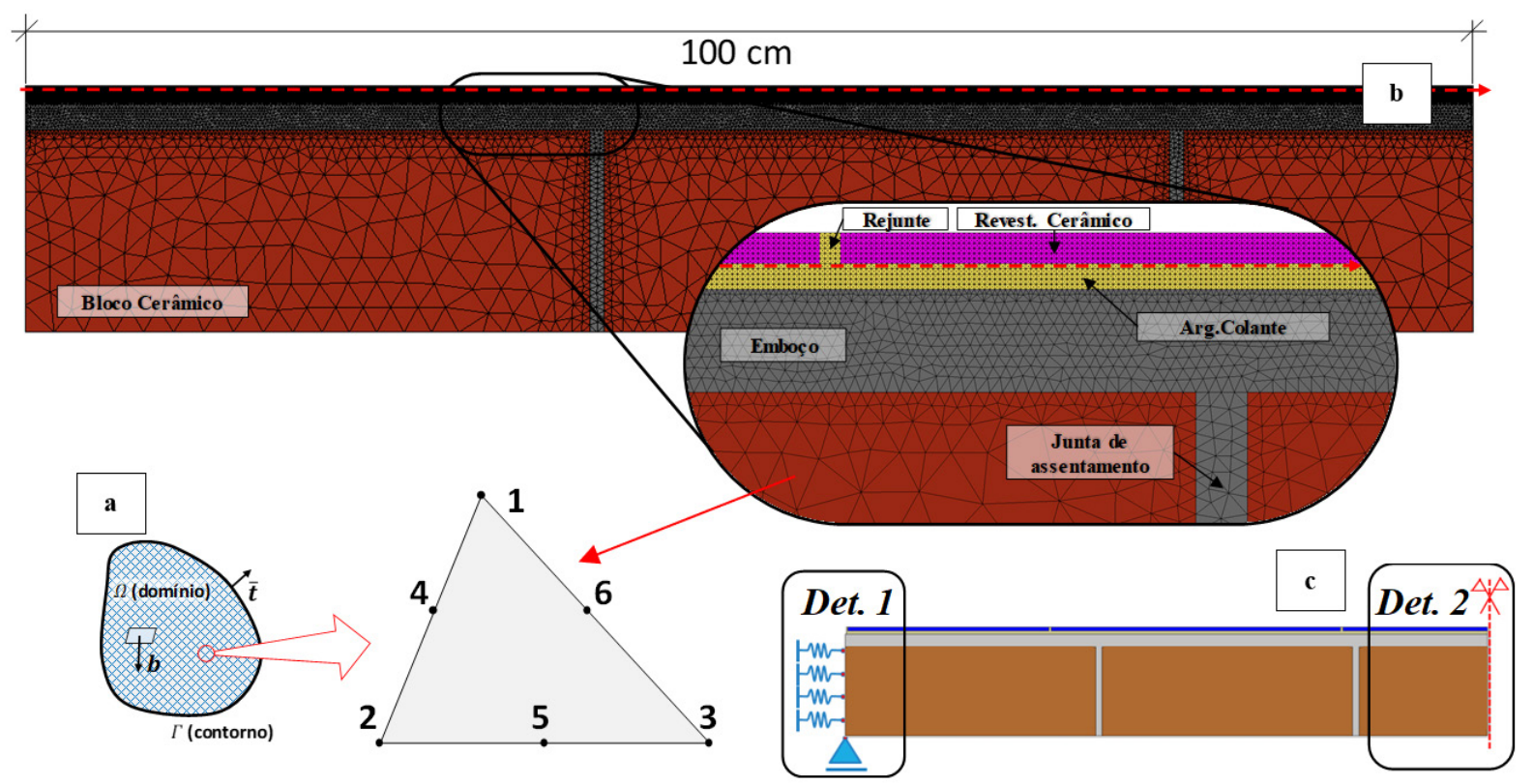

Figura 3. (a) Representação genérica um domínio plano discretizado por elementos finitos triangulares de 6 nós. (b) Malha gerada para estudo dos casos, com indicação de camadas que compõem o SRCA estudado e a linha de interface entre a argamassa colante e o revestimento cerâmico, onde são registradas as tensões atuantes em cada caso. (c) Representação das condições de contorno do problema: simetria à direita e apoio com molas de rigidez variável para representar o confinamento, à esquerda.

Tabela 2. Propriedades geométricas e mecânicas dos elementos componentes do sistema de revestimento, obtidas da literatura $[10,11]$

\begin{tabular}{|c|c|c|c|c|c|c|}
\hline & \multicolumn{6}{|c|}{ Propriedades dos Materiais do Sistema de Revestimento } \\
\hline & $\begin{array}{l}\text { Revestimento } \\
\text { Cerâmico }\end{array}$ & $\begin{array}{l}\text { Argamassa } \\
\text { Colante }\end{array}$ & Rejunte & Emboço & $\begin{array}{c}\text { Juntas de } \\
\text { Assentamento }\end{array}$ & $\begin{array}{l}\text { Bloco } \\
\text { Cerâmico }\end{array}$ \\
\hline $\begin{array}{l}\text { Espessura } \\
(\mathrm{t}, \mathrm{mm})^{\star}\end{array}$ & 6 & 5 & 4 & 20 & 10 & 140 \\
\hline $\begin{array}{l}\text { Módulo } \\
\text { de Young } \\
(\mathrm{E}, \mathrm{MPa})^{*}\end{array}$ & 63300 & 9000 & 9000 & 15000 & 15000 & 60000 \\
\hline $\begin{array}{l}\text { Coef. Poisson } \\
(v, 1)\end{array}$ & 0,22 & 0,21 & 0,21 & 0,22 & 0,23 & 0,20 \\
\hline $\begin{array}{l}\text { Coef. de } \\
\text { Dilatação } \\
\left(\alpha, 1 /{ }^{\circ} \mathrm{C}\right)^{*}\end{array}$ & $7.10^{-6}$ & $7.10^{-6}$ & $7.10^{-6}$ & $7.10^{-6}$ & $7.10^{-6}$ & $7.10^{-6}$ \\
\hline
\end{tabular}

As condições de contorno essenciais do modelo proposto são de um apoio móvel com molas à translação horizontal em uma extremidade (detalhe 1 da Figura 3-c), representando o efeito do confinamento da aduela; e condição de simetria na outra extremidade (detalhe 2 da Figura 3-c) com o objetivo de reduzir a quantidade de elementos e operações necessárias para a aplicação do método. Nesse artigo, foram aplicadas molas de rigidez infinita de maneira a representar um confinamento perfeito da vedação. 
A partir das equações de equilíbrio e condições de contorno do problema, podemos escrever o problema da teoria linear da elasticidade através da Equação (1).

$$
\int_{\Omega} \sigma \cdot \varepsilon \mathrm{d} \Omega=\int_{\Omega} b \cdot u \mathrm{~d} \Omega+\int_{\Gamma} \overline{\boldsymbol{t}} \cdot \boldsymbol{u} \mathrm{d} \Gamma
$$

que deve ser satisfeita para qualquer campo de deslocamentos virtuais $\delta \boldsymbol{u}$. A eq. (1) é conhecida como a formulação integral do problema ou forma fraca [12]. O termo do lado esquerdo é o trabalho virtual dos esforços internos enquanto os termos do lado direito da equação são o trabalho virtual dos esforços externos, contemplando forças volumétricas $\boldsymbol{b}$ e de superfície, $\overline{\boldsymbol{t}}$.

A variação térmica atua no problema deformando o corpo e assim alterando o estado de tensões. A parcela das tensões relativa à mudança de temperatura do modelo deve ser contemplada e está desacoplada da relação constitutiva, como segue a Equação (2).

$$
\sigma=\boldsymbol{D} \cdot \varepsilon+\sigma^{\Delta T} ; \quad \sigma^{\Delta T}=\frac{E \cdot \alpha \cdot \Delta T}{v-1}\left\{\begin{array}{l}
1 \\
1 \\
0
\end{array}\right\} .
$$

sendo $\boldsymbol{D}$ o tensor que associa elasticamente as tensões e deformações do sistema (relação constitutiva). Pode-se observar que a deformação térmica aparece apenas nas direções principais ( $i i$ ), não havendo componente tangencial.

A aproximação do MEF pode ser obtida introduzindo as funções de forma que aproximam os campos de deslocamentos e deformações dentro do subdomínio de cada elemento, em função dos deslocamentos dos seus nós. Dessa forma, temos a Equação (3).

$$
\begin{aligned}
& \boldsymbol{u}(x, y) \mathbf{N}_{\boldsymbol{e}} \mathbf{u}_{\boldsymbol{e}}=\mathbf{N A}_{\boldsymbol{e}} \mathbf{u} ; \\
& \varepsilon(x, y) \mathbf{B}_{\boldsymbol{e}} \mathbf{u}_{\boldsymbol{e}}=(\partial / \partial \boldsymbol{x}) \boldsymbol{u}(x, y)=\mathbf{B}_{\boldsymbol{e}} \mathbf{A}_{\boldsymbol{e}} \mathbf{u},
\end{aligned}
$$

sendo que $\mathbf{N}_{\mathrm{e}}$ é a matriz que interpola os valores de qualquer ponto interno do elemento com relação valores nodais do elemento, $\mathbf{B}_{\mathbf{e}}$ apresenta as derivadas de $\mathbf{N}_{\mathbf{e}}$ com relação a $x$ e $y$ e $\mathbf{A}_{\mathbf{e}}$ é o vetor que associa os graus de liberdade globais aos de cada elemento. As funções de forma adotadas em $\mathrm{N}_{\mathbf{e}}$ são polinomiais quadráticas.

A substituição de (2) e (3) em (1) irá resultar, no domínio local de cada elemento finito deduzido na Equação (4).

$$
\begin{aligned}
& \int_{\Omega_{e}} \sigma \cdot \delta \varepsilon \mathrm{d} \Omega_{e}=\left(\int_{\Omega_{e}} \mathbf{B}_{e}^{T} \mathbf{D}_{e} \mathbf{B}_{e} \mathrm{~d} \Omega_{e}+\int_{\Omega_{e}} \mathbf{B}_{e}^{T} \sigma^{\Delta T} \mathrm{~d} \Omega_{e}\right) \cdot \delta \mathbf{u}_{e} ; \\
& \int_{\Omega_{e}} \boldsymbol{b} \cdot \delta \boldsymbol{u} \mathrm{d} \Omega_{e}=\int_{\Omega_{e}} \mathbf{N}_{e}^{T} \boldsymbol{b} \mathrm{d} \Omega_{e} \cdot \delta \mathbf{u}_{e} \\
& \int_{\Gamma_{e}} \overline{\boldsymbol{t}} \cdot \delta \boldsymbol{u} \mathrm{d} \Gamma_{e}=\int_{\Gamma_{e}} N_{e}^{T} \bar{t} \mathrm{~d} \Gamma_{e} \cdot \delta \boldsymbol{u}_{e} .
\end{aligned}
$$

Após o cálculo das matrizes e vetores locais de todos os elementos finitos e espalhamento nas suas respectivas matrizes e vetores globais, é possível reescrever o problema através do sistema de equações lineares a seguir a Equação (5).

$$
\boldsymbol{K} u+\boldsymbol{f}_{g}^{\Delta T}+\boldsymbol{f}_{\boldsymbol{g}}=0,
$$

no qual o vetor de campo de deslocamentos $\mathbf{u}$ é a incógnita e $\mathbf{K}$ a matriz de rigidez do sistema completo. Obtido o campo de deslocamentos do problema pela resolução de (5), os campos de deformações $(\varepsilon(x, y))$ e tensões $(\sigma(x, y))$ decorrem das equações indicadas em (3) e (2), respectivamente. 


\section{RESULTADOS E DISCUSSÃo}

As Figuras 4, 5 e 6 apresentam as curvas da temperatura dos 4 pontos estudados além de perfil térmico após processo de aquecimento e resfriamento, medidos através protótipo instrumentado. Estas figuras discriminam ainda instantes específicos $(T)$ analisados para cada um dos 3 casos, evidenciando os resultados relacionados ao patamar de aquecimento e de resfriamento. A Tabela 3 apresenta as temperaturas coletadas nos instantes $T$ e os respectivos instantes (min).

O instante T 22 presente do caso 1 foi evidenciado e escolhido de maneira estratégica devido ao acelerado processo de aquecimento e a grande variação entre as medições realizadas nos pontos $\mathrm{P} 1 \mathrm{e}$ P2 relacionados a temperatura da superfície da placa cerâmica e interface entre a placa e a argamassa colante. Nesta situação foram observadas as maiores variações térmicas $(\Delta T)$ entre as camadas analisadas. A elevada taxa de aquecimento provocou uma variação térmica de aproximadamente $4^{\circ} \mathrm{C}$ entre a superfície da placa cerâmica (Ponto 1) e sua interface com a argamassa colante (Ponto 2). Após $1 \mathrm{~h}$ do início do aquecimento a variação térmica entre as camadas foram se tornando cada vez menores devido a troca térmica entre elas até que para o instante T 100 a variação térmica foi de $5,3^{\circ} \mathrm{C}$ para estes mesmos pontos. Iniciado o patamar de estabilização, com controle da temperatura superficial do SRCA, a variação térmica entre as camadas foram se tornando cada vez menores até se obter um patamar próximo da estabilização de temperatura para cada camada.

Com relação ao caso 2, com processo de aquecimento lento, as variações térmicas entre as camadas foram inferiores a $4{ }^{\circ} \mathrm{C}$ ao longo de todo o período de ensaios.

No processo de resfriamento é observada inversão do sentido da troca de calor entre as camadas após a queda da temperatura superficial. Ao exemplo do caso 1, onde no instante T300 a temperatura superficial se apresentava em torno de $83,1^{\circ} \mathrm{C}$, após cessar do aquecimento em 10 min é denotada temperatura de $69^{\circ} \mathrm{C}$ e, portanto, uma queda brusca de temperatura de $14,1^{\circ} \mathrm{C}$.

Para o caso 3, com resfriamento forçado, essas diferenças são ainda maiores. Quando comparado os instantes T20 que representa o final do processo de aquecimento e T24, especificamente 4 min após o processo de resfriamento por água, é observada queda da temperatura superficial em $35,1^{\circ} \mathrm{C}$. Esperados mais $10 \mathrm{~min}(\mathrm{~T} 34)$ a temperatura é reduzida de $83,2{ }^{\circ} \mathrm{C}$ para $31,9{ }^{\circ} \mathrm{C}$ em apenas $14 \mathrm{~min}$, gerando uma variação térmica de $51,3^{\circ} \mathrm{C}$ ou ainda uma taxa média de resfriamento de $3,67^{\circ} \mathrm{C} / \mathrm{min}$ e destaca elevada taxa de fluxo de calor.

Trabalhos como o de Nascimento [15], Bittencourt e Silva [16], Freitas, Carasek e Cascudo [17] apontam elevadas temperaturas em revestimentos de fachada de edifícios e sujeitos a insolação direta em locais como Brasília, Recife e Goiânia, e evidenciam a possibilidade de elevadas temperaturas superficiais e consequente variações térmicas entre as camadas conforme resultados observados.

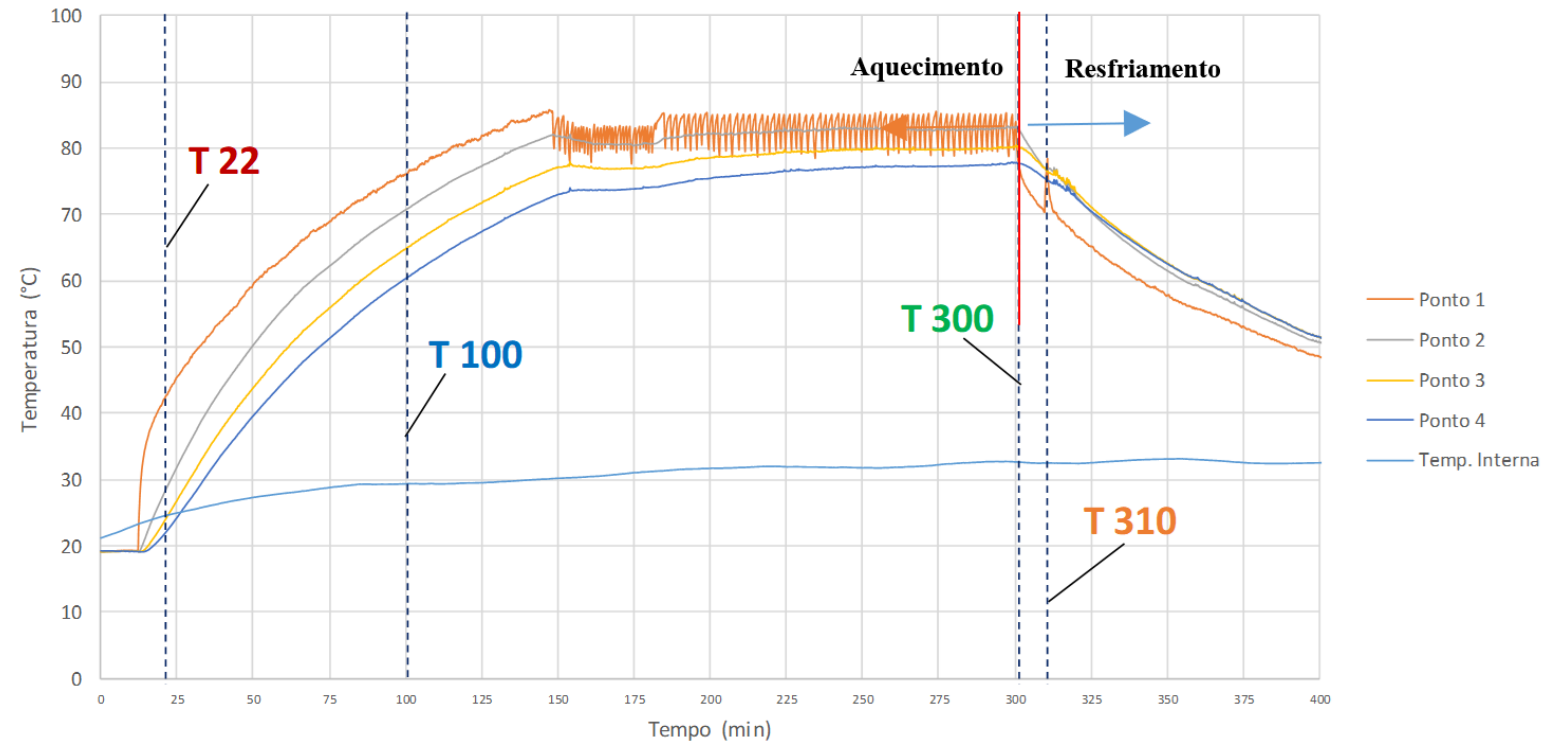

Figura 4 - Curva de evolução das temperaturas nas interfaces para o Caso 1. 


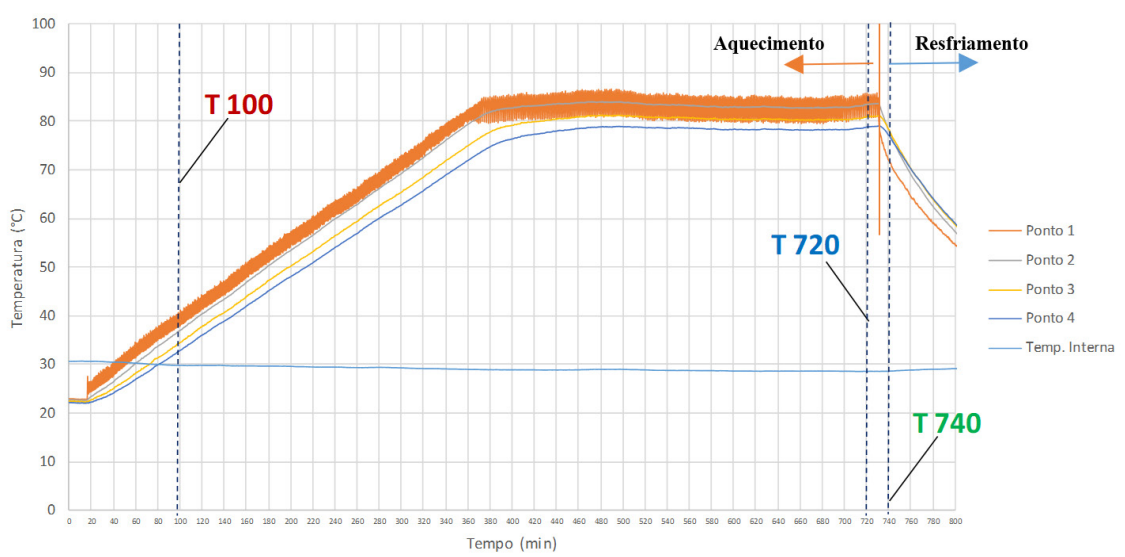

Figura 5. Curva de evolução das temperaturas nas interfaces para o Caso 2, com destaque à etapa de aquecimento do ensaio. O trecho de resfriamento natural obtido não difere substancialmente do resultado avaliado no Caso 1.

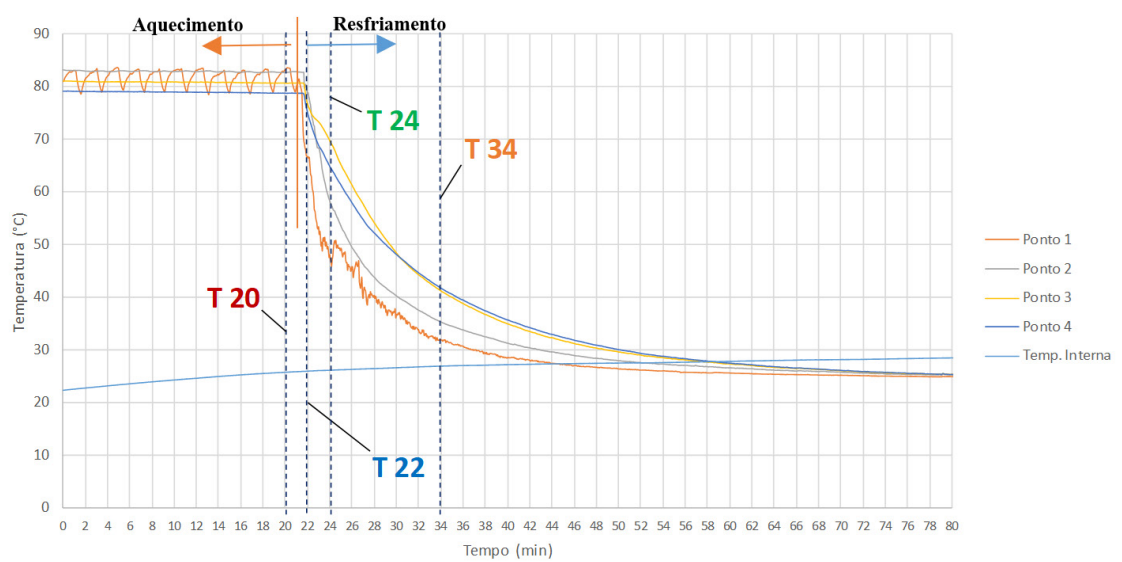

Figura 6. Curva de evolução das temperaturas nas interfaces para o Caso 3, com destaque à etapa de resfriamento forçado do ensaio. $O$ trecho de aquecimento e o patamar obtido não diferem substancialmente do resultado avaliado no Caso 2.

Tabela 3. Resumo das temperaturas capturadas pelos termopares nos pontos das interfaces, para os casos estudados conforme os instantes T. O valor em $\Delta T$ 1,4 é a diferença entre o revestimento (Ponto 1) e a interface substrato-bloco cerâmico (Ponto 4).

\begin{tabular}{|c|c|c|c|c|c|c|c|c|c|c|c|}
\hline Interface/Caso & & & 1 & & & 2 & & & & 3 & \\
\hline Tempo (min) & T 22 & T 100 & T 300 & T 310 & T 100 & T 720 & T 740 & T 20 & T 22 & T 24 & T 34 \\
\hline Ponto $1\left({ }^{\circ} \mathrm{C}\right)$ & 43,1 & 76,0 & 83,1 & 69,0 & 39,0 & 84,6 & 72,0 & 83,2 & 66,5 & 48,1 & 31,9 \\
\hline Ponto $2\left({ }^{\circ} \mathrm{C}\right)$ & 29,2 & 70,7 & 83,0 & 75,4 & 37,0 & 83,4 & 78,2 & 82,7 & 78,5 & 58,3 & 35,3 \\
\hline Ponto $3\left({ }^{\circ} \mathrm{C}\right)$ & 24,6 & 64,8 & 80,2 & 75,4 & 34,5 & 80,9 & 78,4 & 80,7 & 76,7 & 69,7 & 41,2 \\
\hline Ponto $4\left({ }^{\circ} \mathrm{C}\right)$ & 22,5 & 60,3 & 77,8 & 74,2 & 32,9 & 78,8 & 77,1 & 78,7 & 75,0 & 64,8 & 41,7 \\
\hline $\begin{array}{l}\text { Fundo da } \\
\text { parede }\left({ }^{\circ} \mathrm{C}\right)\end{array}$ & 20,0 & 35,0 & 42,0 & 40,0 & 22,0 & 40,0 & 40,0 & 41,0 & 41,0 & 40,0 & 38,0 \\
\hline$\Delta \mathrm{T} 1,4$ & $+20,6$ & $+15,7$ & $+5,3$ & $-5,2$ & $+6,1$ & $+5,8$ & $-5,1$ & $+4,4$ & $-8,6$ & $-16,8$ & $-9,8$ \\
\hline
\end{tabular}

As Figuras 7, 8 e 9 apresentam o modelo computacional MEF com gradiente de cores ao longo do modelo representativo do SRCA e suas respectivas camadas.

As tensões principais máximas ( $\sigma_{1}$, em MPa) e de cisalhamento $\left(\tau_{x y}\right.$, em MPa) ao longo do comprimento da interface entre a placa cerâmico e a argamassa colante são representadas através dos gráficos de linhas além de respectiva modelagem e ilustração gráfica. Acima do modelo é apresentado o gráfico de $\sigma_{1}$ com respectivo gradiente e localizações geradas pela variação de temperatura nos instantes 
T conforme mencionados anteriormente. As figuras demonstram os resultados de tensões geradas através da influência dos parâmetros perfis de temperatura, geometria das camadas e propriedades mecânicas considerados em cada caso na geração das tensões ao sistema.

Em todos os casos foi observado o surgimento de picos de tensão na borda esquerda do modelo, onde a vinculação causada pela aduela foi introduzida por meio de molas. A adoção de engaste (rigidez infinita) restringiu o deslocamento e a rotação livre entre as camadas deste lado e gerou as tensões adicionais observadas, geradas pelo processo de confinamento e, portanto, a elevação dos picos de tensões na ligação entre o elemento confinante de concreto e o SRCA modelado apresentado em branco e fora da escala de cores. Do contrário, tal comportamento não ocorre no lado direito (simetria), visto que existe a continuidade do SRCA e apenas os deslocamentos laterais foram restringidos. Vê-se que esse efeito é local e suaviza após $10 \mathrm{~cm}$ de distância da borda, não afetando os resultados em distâncias menores que estas e localizadas ao centro da placa cerâmica.

Além disso, todas as tensões locais máximas observadas estão contidas na região interna ou limítrofe dos rejuntes, considerando a linha da interface entre argamassa colante e revestimento cerâmico, que chega a ter tensões de tração e de cisalhamento superiores a 2,0 MPa. Resultados semelhantes já foram previamente verificados por Abreu et al. [18] e Herwegh et al. [10] apesar de diferenças nas condições de apoio e carregamento do sistema.

Nos modelos apresentados são encontrados elevados níveis de tensões nas bordas dos elementos do SRCA nos quais são ligados através de argamassas, seja argamassa de rejuntamento como o caso das juntas de assentamento entre as placas, argamassa colante, ou ainda nas argamassas de emboço e de assentamento dos blocos da alvenaria. Estas áreas apresentam concentração de tensões acima da capacidade resistentes dos materiais cimentícios utilizados, podendo acarretar a ruptura destas argamassas nessas regiões.

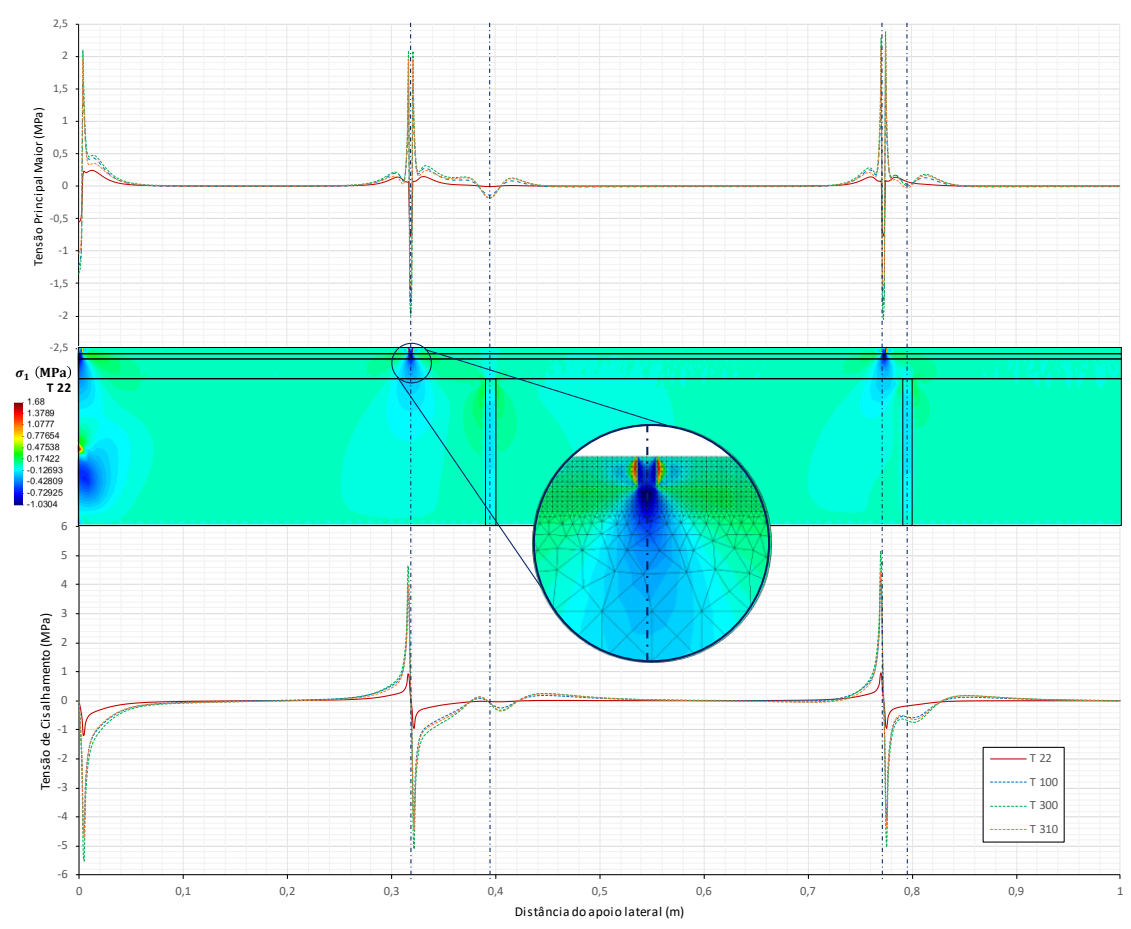

Figura 7. Tensão principal $\left(\sigma_{1}\right)$ e de cisalhamento $\left(\tau_{x y}\right)$ ao longo da argamassa colante na interface com o revestimento cerâmico para o Caso $\mathrm{C} 1$. No detalhe, representação da malha adotada na região do rejunte entre placas, com pico local de tensão principal. As retas tracejadas verticais indicam a posição dos efeitos localizados nos resultados, promovidos pela geometria do modelo.

Ainda que em menor intensidade, outros picos locais de tensão foram originados pelas juntas de assentamento entre blocos, conforme indicação em linha vertical tracejada azul das Figuras 7, 8 e 9 . A avaliação da influência desses picos relacionados a presença dos blocos da base em alvenaria caso 
coincidentes com a posição das juntas de rejuntamento entre placas levanta a hipótese da combinação das tensões gerando uma fragilidade no sistema caso estiverem na mesma posição.

Ainda, para ambos os casos, é observado que as maiores tensões encontradas estão relacionadas às maiores temperaturas das camadas e não aos seus respectivos gradientes térmicos entre camadas. Em outras palavras, sistemas sujeitos a maiores temperaturas estão mais propensos a picos mais elevados de tensão do que aqueles com maiores variações térmicas entre as camadas. O comportamento pode ser explicado pelas expansões térmicas das camadas oriundas dos seus coeficientes de dilatação térmico e aumento de seus volumes em função do aumento da temperatura. Por estas camadas estarem confinadas tanto em suas adjacências quanto aderidas umas às outras, torna possível o surgimento destas tensões. A Tabela 4 apresenta os valores máximos e mínimos de tensão observados nos rejuntes para cada caso estudado.

O processo de prototipagem em grande escala possibilitou não somente a obtenção das propriedades para o processo de modelagem computacional como também observar os fenômenos apresentados através dos modelos em condições reais após o protótipo ser submetido a ciclos de aquecimento e resfriamento. Tal processo ocasionou uma série de fissuras nas juntas de rejuntamento, verificadas e mapeada no protótipo (Figura 8-a e Figura 8-b), evidenciando a concentração de tensões na região de rejunte. Essa maior propensão às fissuras também foi previamente relatada por Mansur et al. [3], através da observação de patologias relacionadas a desplacamentos em sistemas de fachadas do Brasil, como consequência de ciclos de molhamento e secagem e tensões altas significativas, por exemplo.

O protótipo também evidenciou as solicitações apresentadas no modelo computacional quanto a presença de tensões relacionadas a interferência dos blocos no sistema aderido. Suas quinas se apresentaram propensas a solicitações tanto das juntas entre blocos quanto do emboço. Fissuras foram encontradas nesta região e validam os resultados apresentados pelos modelos (Figura 8-c).

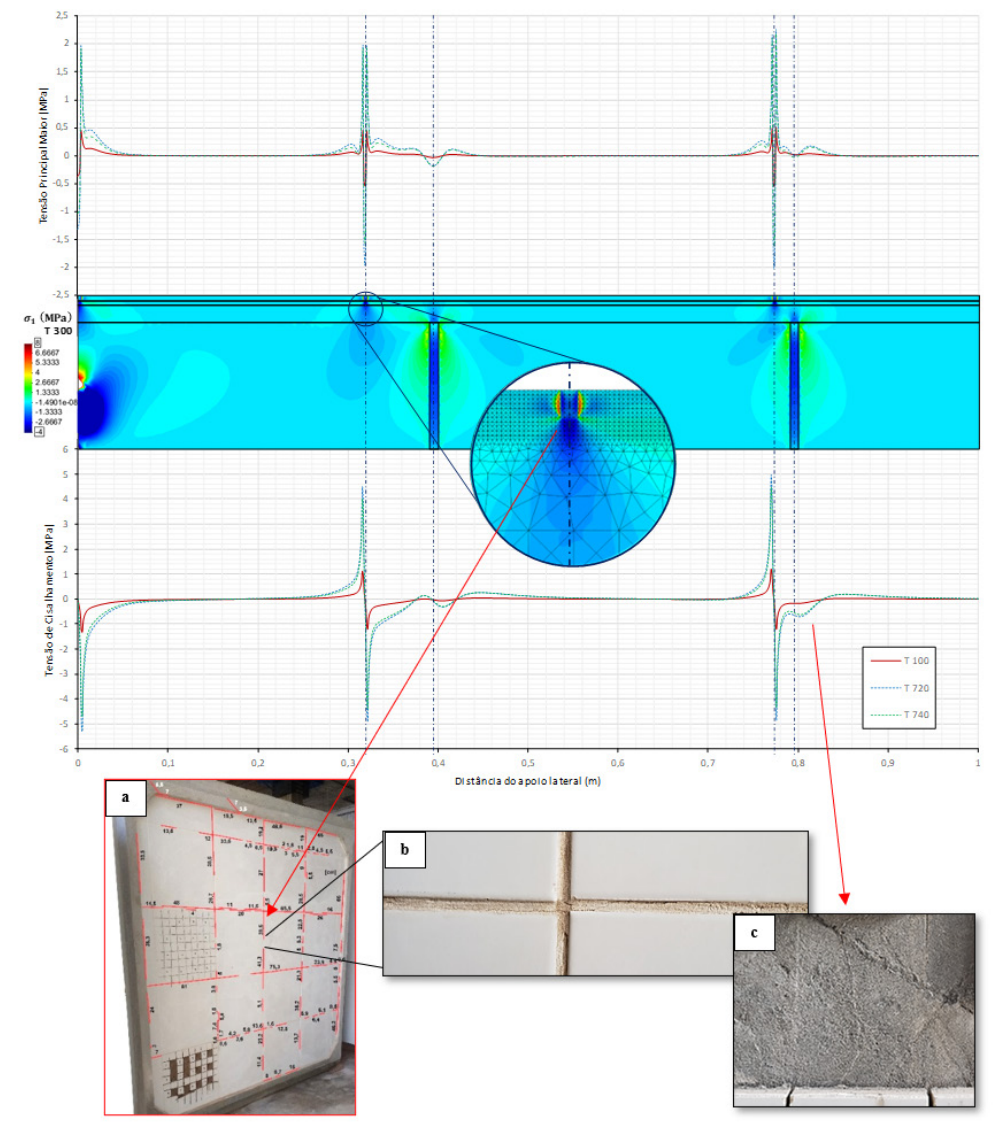

Figura 8. Tensão principal $\left(\sigma_{1}\right)$ e de cisalhamento $\left(\tau_{x y}\right)$ ao longo da argamassa colante na interface com o revestimento cerâmico para o Caso C2. No detalhe, representação da malha adotada na região do rejunte entre placas, com pico local de tensão principal. As retas tracejadas verticais indicam a posição dos efeitos localizados nos resultados, promovidos pela geometria do modelo. (a) Mapeamento com indicação do surgimento de fissuras no rejunte após ciclos de choque térmico. (b) Surgimento de fissura nas juntas. (c) Fissuração no emboço. 


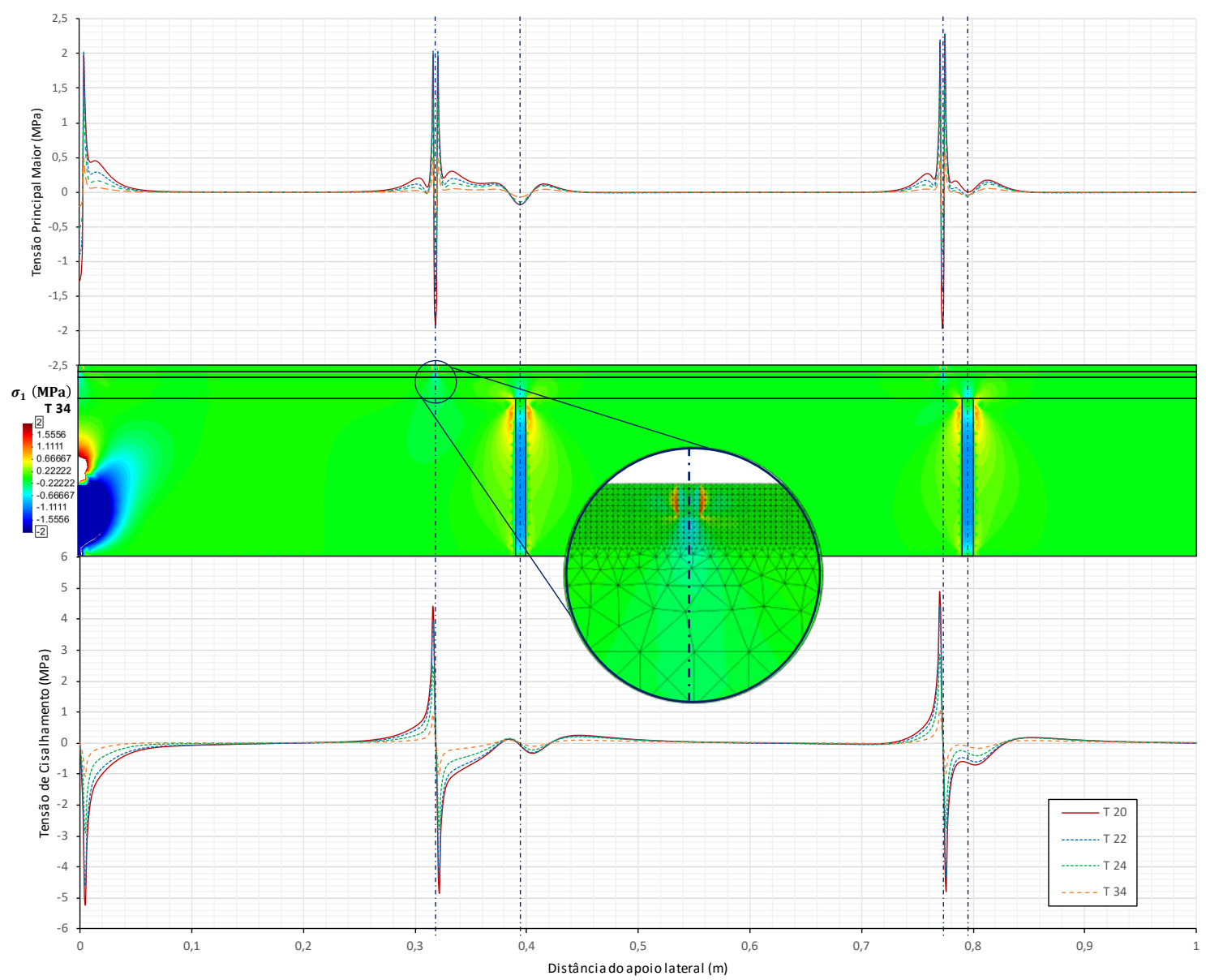

Figura 9. Tensão principal $\left({ }^{\sigma_{1}}\right)$ e de cisalhamento $\left({ }^{\tau_{x y}}\right)$ ao longo da argamassa colante na interface com o revestimento cerâmico para o Caso C3. No detalhe, representação da malha adotada na região do rejunte entre placas, com pico local de tensão principal. As retas tracejadas verticais indicam a posição dos efeitos localizados nos resultados, promovidos pela geometria do modelo.

Tabela 4. Valores das tensões máximas e mínimas observadas nas regiões do rejunte na linha de interface entre argamassa e revestimento cerâmico

\begin{tabular}{|c|c|c|c|c|c|}
\hline \multirow{2}{*}{\multicolumn{2}{|c|}{ Caso/Tempo }} & \multicolumn{4}{|c|}{ Rejunte à esquerda (valores em MPa) } \\
\hline & & \multirow{2}{*}{$\begin{array}{c}\boldsymbol{\sigma} 1 \text { máx } \\
0,13\end{array}$} & \multirow{2}{*}{$\begin{array}{c}\boldsymbol{\sigma} 1 \text { mín } \\
-0,76\end{array}$} & \multirow{2}{*}{$\begin{array}{c}\text { txy máx } \\
0,95\end{array}$} & \multirow{2}{*}{$\begin{array}{c}\text { xxy mín } \\
-0,99\end{array}$} \\
\hline C1 & T 22 & & & & \\
\hline & $T 100$ & 1,60 & $-1,75$ & 3,92 & $-4,08$ \\
\hline & T 300 & 2,10 & $-2,00$ & 4,62 & $-5,00$ \\
\hline & T 310 & 1,92 & $-1,56$ & 4,00 & $-4,40$ \\
\hline \multirow[t]{3}{*}{$\mathrm{C} 2$} & $T 100$ & 0,45 & $-0,52$ & 1,17 & $-1,10$ \\
\hline & $T 720$ & 1,97 & $-1,95$ & 4,50 & $-4,95$ \\
\hline & $T 740$ & 1,95 & $-1,55$ & 4,00 & $-4,40$ \\
\hline \multirow[t]{4}{*}{ C3 } & T 20 & 1,95 & $-1,92$ & 4,42 & $-4,88$ \\
\hline & T 22 & 2,05 & $-1,38$ & 4,95 & $-4,38$ \\
\hline & T 24 & 1,35 & $-0,80$ & 2,30 & $-2,80$ \\
\hline & T 34 & 0,49 & $-0,30$ & 0,90 & $-1,05$ \\
\hline
\end{tabular}

\begin{tabular}{cccccc}
\multicolumn{2}{c}{ Caso/Tempo } & \multicolumn{4}{c}{ Rejunte à direita (valores em MPa) } \\
\cline { 3 - 6 } C1 & T 22 & 0,14 & $-0,76$ & 0,95 & $-0,99$ \\
& $T 100$ & 1,80 & $-1,80$ & 4,10 & $-4,05$ \\
& $T 300$ & 2,38 & $-2,05$ & 5,18 & $-5,00$ \\
& $T 370$ & 2,20 & $-1,60$ & 4,45 & $-4,40$ \\
C2 & $T$ 100 & 0,51 & $-0,55$ & 1,20 & $-1,20$ \\
& $T$ 720 & 2,26 & $-2,02$ & 5,00 & $-4,83$ \\
& $T 740$ & 2,18 & $-1,60$ & 4,45 & $-4,38$ \\
C3 & $T 20$ & 2,25 & $-1,98$ & 4,90 & $-4,80$ \\
& $T 22$ & 2,30 & $-1,41$ & 4,40 & $-4,30$ \\
& $T 24$ & 1,55 & $-0,81$ & 2,82 & $-2,80$ \\
& $T 34$ & 0,58 & $-0,31$ & 1,10 & $-1,00$ \\
\hline
\end{tabular}




\section{CONCLUSÕES}

Um estudo que envolve prototipagem com instrumentação, análise laboratorial por meio de corpo de prova em grandes dimensões, caracterização dos materiais e análise computacional, são algumas das contribuições propostas através das rotinas e processos implementados pelos autores. Essa abordagem permitiu um melhor tratamento dos dados e um melhor embasamento para se elaborar modelos computacionais. Modelos assim contemplam uma maior riqueza de detalhes da geometria das camadas, suas propriedades térmicas e mecânicas e permitem a visualização de tensões relacionadas as variações térmicas com base em curvas de aquecimento. Tais modelagens demonstram deformações e comportamentos mais fidedignos ao que se espera para o campo de temperaturas e os resultados esperados para um SRCA real.

Neste sentido, o trabalho buscou avaliar como se comportam as diferentes camadas do SRCA quando submetidos a diferentes taxas de aquecimento e resfriamento além de apresentar as tensões originadas por estas diferentes simulações. Não apenas as taxas de aquecimento e resfriamento induzem tensões internas nas camadas destes sistemas, mas também a presença dos elementos como as juntas de assentamento das placas cerâmicas e blocos são grandes potencializadores destas solicitações. Concentrações de tensões foram observadas nas juntas das placas e observadas na forma de danos nos rejuntes que, se porventura coincidirem com as juntas de assentamento dos blocos, podem gerar danos ainda mais graves ao SRCA.

A elevação da temperatura na superfície do revestimento acelera a troca de calor entre as camadas e consequentemente induz ao surgimento de tensões de maneira distinta entre elas. Neste sentido o processo de aquecimento e a observação de maiores temperaturas superficiais são aquelas que apresentaram maiores tensões através dos resultados de modelagem obtidos.

O protótipo desenvolvido em laboratório evidenciou a concentração de tensões através do surgimento de fissuras nas argamassas de rejuntamento antes evidenciadas por meio da modelagem computacional e relacionadas as bordas das placas cerâmicas. As juntas de assentamento dos blocos de alvenaria também são potencializadoras de surgimento de tensões e geram solicitações da camada de regularização adjacente, sendo possível observar o surgimento de fissuras nas regiões de contorno dos blocos. Portanto, as argamassas e suas respectivas camadas aquelas que mais sofrem com estes processos.

Este trabalho faz parte de um estudo mais amplo, ainda em fase inicial, e que buscará esclarecer e quantificar a influência de diversos parâmetros que afetam na distribuição e localização de picos de tensão e, por consequência, no desempenho do SRCA. Estudos estão sendo desenvolvidos com a utilização de argamassas com diferentes propriedades, principalmente a variação do módulo de elasticidade, e os comportamentos com elas observados através da modelagem computacional e prototipagem. Além disso, serão incorporados no modelo computacional vazios na camada de argamassa colante, que simulem a falha no assentamento e implementação da mecânica do mano simulada através de MEF para se conseguir avaliar a redistribuição de tensões após atingidas as tensões máximas resistentes da argamassa.

\section{AGRADECIMENTOS}

Os autores agradecem o apoio da Associação Nacional dos Fabricantes de Cerâmicas (ANFACER), da Associação Paulista das Cerâmicas de Revestimento (ASPACER) e dos Laboratórios de Materiais, Componentes e Processos Construtivos (LMCP/PCC) e de Mecânica Computacional (LMC/PEF) dos Departamentos de Engenharia Civil da Escola Politécnica da Universidade de São Paulo - POLI-USP.

\section{REFERÊNCIAS}

[1] E. Bauer, E.K. De Castro, G.R. Antunes, F.E. Leal, Identification and Quantification of Failure Modes of New Buildings Façades in Brasília, XII DBMC - Int. Conf. Durab. Build. Mater. Components. (2011) 1-7.

[2] M.Y.L. Chew, Factors affecting ceramic tile adhesion for external cladding, Constr. Build. Mater. 13 (1999) 293-296. https://doi. org/https://doi.org/10.1016/S0950-0618(99)00023-9.

[3] H.S. Mansur, A. A. P; Nascimento, O. L.; Mansur, Data collection of five years of exterior facade pathologies in Brazil, in: Qualicer 2006, Castellón, 2006: pp. 107-120.

[4] L.M. Pezzato, E.P. Sichieri, Patologias no Sistema Revestimento Cerâmico : Análise sobre o Atendimento ao Consumidor Realizado pelo Centro Cerâmico do Brasil, Cerâmica Ind. (2008) 11-13. 
[5] H.C.F. Curci, E.M.B. Campello, H.C. Campelo, F.L. Maranhão, R.P. Andrade, Método dos elementos finitos com mecânica do dano aplicada à avaliação do desempenho de sistemas de revestimento cerâmico sob indução de fluxo térmico controlado, $61^{\circ}$ Congr. Bras. Do Concreto - CBC 2019. (2019) 1-16.

[6] C.Y. Yiu, D.C.W. Ho, S.M. Lo, Weathering effects on external wall tiling systems, Constr. Build. Mater. 21 (2007) 594-600. https:// doi.org/10.1016/j.conbuildmat.2005.11.002.

[7] R.P. de Andrade, M.M. Resende, F.L. Maranhão, Avaliação de fatores que influenciam para o destacamento de revestimentos cerâmicos, XII Simpósio Bras. Tecnol. Das Argamassas - SBTA 2017. (2017).

[8] T. Mahaboonpachai, Y. Kuromiya, T. Matsumoto, Experimental investigation of adhesion failure of the interface between concrete and polymer-cement mortar in an external wall tile structure under a thermal load, Constr. Build. Mater. 22 (2008) 2001-2006. https://doi.org/10.1016/j.conbuildmat.2007.07.002.

[9] J.K. Felixberger, Polymer-modified thin-bed tile adhesives, Augsburg, 2008.

[10] M. Herwegh, R. Zurbriggen, R. Mettier, F. Winnefeld, J. Kaufmann, A. Wetzel, Hygrical shrinkage stresses in tiling systems: Numerical modeling combined with field studies, Cem. Concr. Compos. 55 (2015) 1-10. https://doi.org/10.1016/j.cemconcomp.2014.06.016.

[11] R. Zurbriggen, M. Herwegh, Daily and seasonal thermal stresses in tilings: a field survey combined with numeric modeling, Mater. Struct. 49 (2016) 1917-1933. https://doi.org/10.1617/s11527-015-0623-5.

[12] J. Fish, T. Belytschko, A First Course in Finite Elements, Wiley, 2007.

[13] A.F. Bower, Applied Mechanics of Solids, Taylor \& Francis, Boca Raton, 2010.

[14] R. Ribó, M.A. de R. Pasenau, E. Escolano, GiD Reference Manual, (2000) 278

[15] M.L.M. Nascimento, Aplicação da Simulação Higrotérmica na Investigação da Degradação de Fachadas de Edifícios, 2016. http:// scholar.google.com/scholar?hl=en\%7B\&\%7DbtnG=Search\%7B\&\%7Dq=intitle:Universidade+de+Bras\%7Bí\%7Dlia\%7B\#\%7D9.

[16] S.M. Bittencourt, F.A.G. Silva, Comportamento da temperatura de fachadas confrontantes de edifícios e sua contribuição para a formação de ilhas de calor, (2007) 230-239.

[17] J.G. de Freitas, H. Carasek, O. Cascudo, Utilização de termografia infravermelha para avaliação de fissuras em fachadas com revestimento de argamassa e pintura, Ambient. Construído. 14 (2014) 57-73. https://doi.org/10.1590/S1678-86212014000100006.

[18] M. Abreu, V. Leitão, J.C. Lucas, Modeling the behavior of ceramic tile covering, in: VIII WORLD Congr. Ceram. TILE Qual. QUALICER 2004, Castellón: Logui Impresión, Castellón, Spain, 2004: p. P.GII-3-P.GII-17. 